\title{
LA TEMPORALIDAD DE LAS SEPULTURAS MEGALÍTICAS TIPO THOLOS DEL SUR DE LA PENÍNSULA IBÉRICA
}

\author{
THE TEMPORALITY OF THE MEGALITHIC THOLOS-TYPE TOMBS IN SOUTHERN IBERIA
}

\author{
ÁGUEDA LOZANO MEDINA* / GONZALO ARANDA JIMÉNEZ**
}

\begin{abstract}
Resumen: El reciente incremento del número de dataciones radiocarbónicas de sepulturas tipo tholos permite establecer diferentes consideraciones sobre la temporalidad de este fenómeno megalítico. El modelado bayesiano de la nueva serie radiométrica de 41 dataciones sitúa el inicio de este nuevo tipo de arquitectura megalítica en la transición entre el IV y III milenios (3070-2900 cal BC al 68\% de probabilidad) y su final entre los siglos IX-VIII cal BC $(890-710$ cal BC al $68 \%$ de probabilidad) coincidiendo con el final de la Edad del Bronce. Durante este extenso periodo (2000-2213 años al 68\% de probabilidad) solo se documenta un posible hiatus en torno al c. 1550 cal BC coincidiendo con la crisis de las sociedades del Bronce Pleno. La intensidad en el uso ritual de los tholoi durante la Edad del Bronce es sin duda una de las más importantes aportaciones de la nueva serie radiocarbónica. Además, la distribución territorial de las dataciones descarta cualquier tipo de diferenciación temporal entre las diferentes comarcas analizadas.
\end{abstract}

Palabras clave: Megalitismo, sepultura de falsa cúpula, datación radiocarbónica, estadística Bayesiana, Edad del Cobre, Edad del Bronce, Península ibérica.

\section{INTRODUCCIÓN}

En términos generales, el estudio del fenómeno megalítico en el sur de la península ibérica se enfrenta a importantes limitaciones. La escasa calidad de la

\footnotetext{
* Departamento de Prehistoria y Arqueología de la Universidad de Granada. Campus de Cartuja s/n, 18071, Granada. Correo-e: aguedalozanomed@gmail.com
}

\begin{abstract}
According to new radiocarbon dates of tholos-type tombs new insights in the temporality of this megalithic phenomenon in southern Iberia can be explored. The Bayesian modelling of 41 dates sets the appearance of this megalithic architecture in the transition among the fourth and third millennia (3070-2900 cal BC at $68 \%$ probability) and its end in the IX-VIII centuries cal BC $(890-710 \mathrm{cal} \mathrm{BC}$ at $68 \%$ probability), matching with the end of the Bronze Age. During this very long period (2000-2213 years at $68 \%$ probability), a short hiatus is documented around c. $1550 \mathrm{cal}$ BC when dramatic cultural changes occurred in Bronze Age societies. Two main contributions of the new radiocarbon series can be highlighted: the intensity in ritual use of tholoi tombs during the Bronze Age and the lack of any temporal differences between the different regions of southern Iberia.
\end{abstract}

Keywords: Megalithic Phenomenon, Tholos-type Tombs, Radiocarbon Dating, Bayesian Modelling, Copper Age, Bronze Age, Iberian Peninsula.

información es una de ellas. La base documental actualmente disponible procede fundamentalmente de excavaciones antiguas, realizadas entre finales del siglo XIX y primera mitad del siglo XX y donde los protocolos de documentación eran, en el mejor de los casos, de escasa

\footnotetext{
** Departamento de Prehistoria y Arqueología de la Universidad de Granada. Campus de Cartuja s/n, 18071, Granada. Correo-e: garanda@ugr.es
} 
precisión. Este sería el caso de los trabajos realizados en el sureste peninsular por Luis Siret y su colaborador Pedro Flores, quienes excavaron la mayoría de las necrópolis megalíticas almerienses y granadinas conocidas (Siret 1891 [2001], 1906-7 [1994]; Leisner y Leisner 1943). En épocas más recientes las intervenciones arqueológicas realizadas han registrado otro fenómeno que añade igualmente incertidumbre. La inmensa mayoría de las sepulturas megalíticas ha sido objeto de expolio desde tiempos inmemoriales, lo que ha motivado que la información recuperada sea incompleta y fragmentaria.

La cronología absoluta del megalitismo es otra relevante limitación. El número de dataciones radiocarbónicas actualmente disponible es claramente insuficiente, a pesar de que entre las primeras dataciones de la Prehistoria Reciente peninsular se encuentren las realizadas para las necrópolis megalítica de Los Millares (Schwabedissen y Freundlich 1966) y El Barranquete (Almagro 1973). En los últimos años, sin embargo, el número de dataciones ha comenzado a incrementarse de forma notable. Este es el caso de las sepulturas tipo tholos para las que en 2011 sólo se disponía de 10 fechas (García Sanjuán et al. 2011), que se han incrementado hasta las 41 actuales (tabla 1). Aunque el número total sigue siendo exiguo, no obstante es posible establecer diferentes valoraciones sobre la temporalidad de estas construcciones y de las prácticas rituales asociadas. Precisamente, este será el principal objetivo del presente trabajo, que abordará en primer lugar las características que definen e identifican este tipo de sepulcros, para posteriormente analizar la cronología de los tholoi a partir de su serie radiométrica.

\section{SEPULTURAS DE FALSA CÚPULA EN EL SUR PENINSULAR}

En la península ibérica las sepulturas tipo tholos constituyen un fenómeno característico de su parte meridional, donde se producen las principales concentraciones en regiones como Andalucía, Extremadura, el Algarve o el Alentejo, estas dos últimas en Portugal. A lo largo de este extenso territorio, los tholoi se caracterizan fundamentalmente por la forma en falsa cúpula que adopta la cubierta de sus cámaras funerarias. Este sistema constructivo consiste en hiladas de mampostería superpuestas que van reduciendo progresivamente su diámetro.

1. En este artículo el concepto tholos se utiliza exclusivamente desde una perspectiva arquitectónica sin que suponga asumir ninguna de las connotaciones que historiográficamente ha tenido.
Habitualmente los tholoi presentan cámara y corredor de acceso, en la mayoría de los casos excavados parcialmente en la matriz geológica. La cámara principal es de planta ovalada o circular con un diámetro que se sitúa por regla general entre los 2 y $4 \mathrm{~m}$. Sus paredes son de mampostería que en ocasiones parten desde el suelo de la cámara, en otras desde el talud creado por el soterramiento parcial de la misma, o desde grandes ortostatos dispuestos verticalmente que conforman un cuerpo inferior en el alzado de la cámara. Frecuentemente, desde las cámaras principales se accede a otras secundarias siempre de menores dimensiones.

Los corredores de acceso suelen presentar planta rectangular o trapezoidal. En su construcción se emplean igualmente muros de mampostería con una cubierta adintelada formada por ortostatos. Los corredores aparecen habitualmente divididos en tramos, a partir del empleo de puertas diferenciadas con jambas y dinteles, simples peldaños o mediante lajas de piedra perforadas. En algunos tholoi, frente al corredor se documenta un área de forma rectangular o trapezoidal denominada como vestíbulo y definida a partir de ortostatos situados verticalmente o muros de mampostería. Finalmente, las sepulturas quedarían cubiertas por túmulos formados por capas de tierra y piedra y delimitados por uno o varios anillos de mampostería.

Las dimensiones de estas estructuras varían considerablemente, desde tholoi de tamaños modestos, caso por ejemplo de la necrópolis de El Barraquete cuyas cámaras oscilan entre los 3 y 4 m de diámetro, los corredores no superan los 3,5 m de longitud y los túmulos de mayores dimensiones alcanzan los $16 \mathrm{~m}$ de diámetro (Almagro 1973), hasta sepulturas de grandes dimensiones y monumentalidad. En este último caso sobresalen especialmente dólmenes como la Pastora, cuyo corredor alcanza los $42 \mathrm{~m}$ de longitud (García Sanjuán 2009), o El Romeral con un túmulo de 75 m de diámetro (Márquez Romero 2009).

No siempre es sencillo determinar a partir de los restos arqueológicos conservados si una sepultura forma o no parte de este tipo de construcciones megalíticas. En aquellas ocasiones donde las sepulturas presentan cámara de planta circular y corredor de acceso, pero donde debido a las condiciones de conservación no ha podido identificarse con claridad el sistema de cubrición de la cámara, se han producido ciertas dudas sobre su adscripción tipológica. Este sería el caso, por ejemplo, de la sepultura de Castro Marim (Castro Marim, Algarve) considerada inicialmente como tholos (Zbyszewski y Ferreira 1967), lo que posteriormente ha sido cuestionado por la falta de evidencias concluyentes sobre 


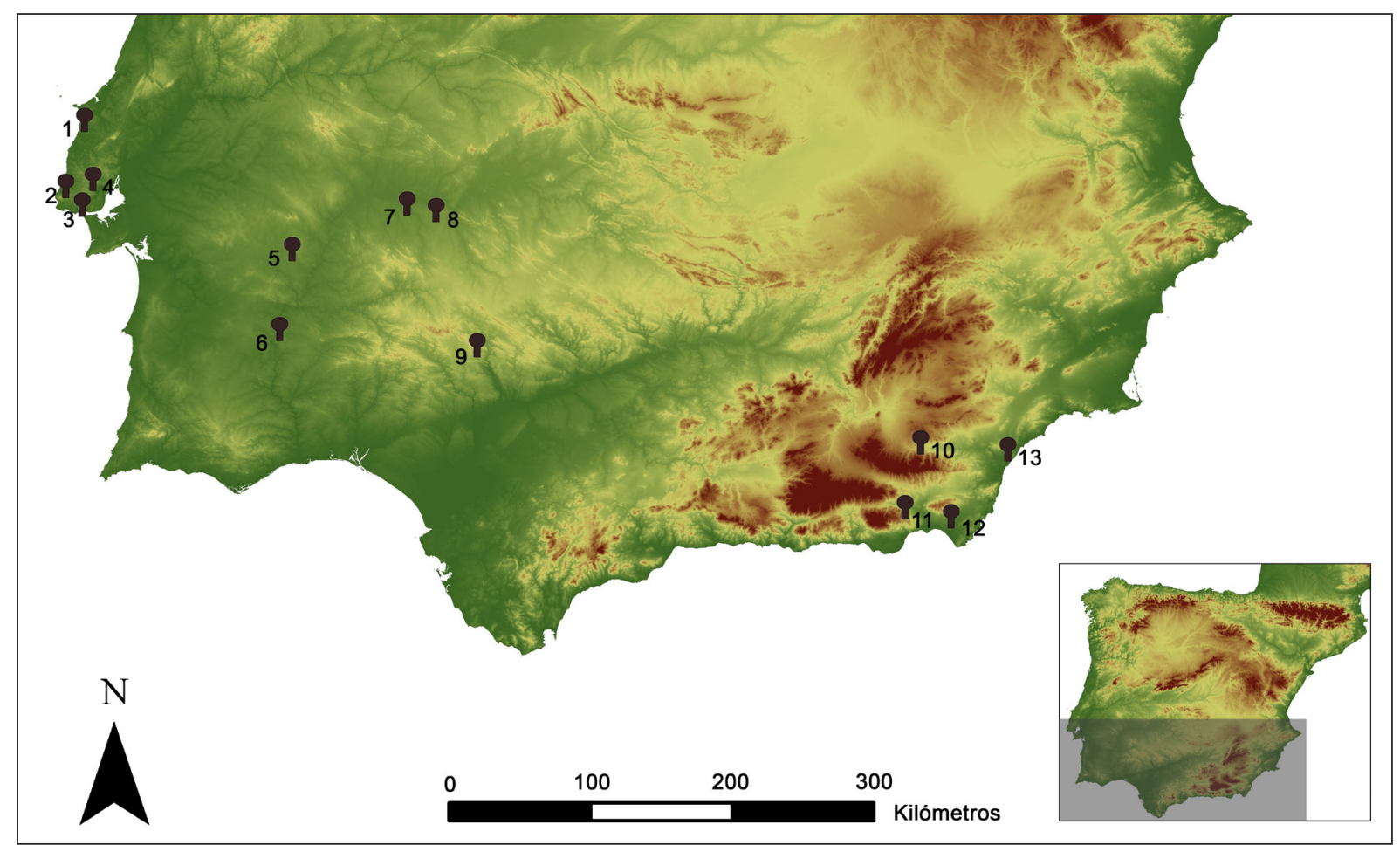

Figura 1. Localización de las necrópolis y sepulturas de tipo tholos con dataciones radiocarbónicas. 1 Paimogo. 2 Praia das Maçãs. 3 Agualva. 4 Tituaria. 5 Olival da Pega 2b. 6 Centirã 2. 7 La Pijotilla. 8 Huerta Montero. 9 Palacio III. 10 Loma del Llano del Jautón. 11 Los Millares. 12 El Barranquete. 13 La Encantada I.

la presencia de falsa cúpula (Gomes et al. 1994), o de Cabeço da Arruda 2 (Torres Vedras, Lisboa), sepultura para la que se ha propuesto una cubierta adintelada (Ferreira y Trindade 1956). En otras ocasiones como en el dolmen de Montelirio (Castilleja de Guzmán, Sevilla) la documentación de hoyos de poste en el interior de sus dos cámaras funerarias apuntaría a un sistema de cubrición diferente al de aproximación de hiladas, lo que ha descartado su consideración como tholos (Fernández y Aycart 2013). En la tabla 1 presentamos sólo aquellos tholoi con dataciones radiocarbónicas para los que existen evidencias concluyentes sobre la presencia de falsa cúpula o en los que, al menos, los indicios arqueológicos documentados han permitido razonablemente su inclusión dentro de este tipo de sepulturas megalíticas.

\section{CRONOLOGÍA DE LAS SEPULTURAS DE FALSA CÚPULA}

La irrupción a partir de los años 60 de la cronología radiocarbónica en el estudio de las sociedades prehistóricas supuso para el caso del fenómeno megalítico el final de los modelos difusionistas, que hacían depender cualquier innovación cultural de la llegada de colonizadores extrapeninsulares. Las primeras dataciones de C14 confirmaron que las construcciones megalíticas eran más antiguas que los pueblos del mediterráneo oriental de los que supuestamente procedían (Renfrew 1973, 1979). A pesar de la importancia que la cronología numérica tuvo en el cambio hacia modelos de interpretación autoctonistas, apenas si ha tenido un desarrollo posterior. Solo en los últimos años la datación del fenómeno megalítico ha comenzado a formar parte de las agendas de investigación. El caso de las sepulturas tipo tholos ha sido paradigmático. Como se ha indicado anteriormente, solo en los últimos cuatro años se ha producido un aumento considerable, pasando de 10 a las 41 dataciones actualmente disponibles.

Esta nueva serie radiocarbónica posee algunas debilidades más allá de su exiguo número. Su distribución geográfica es una de ellas. Extensos territorios con importantes concentraciones megalíticas carecen de dataciones (fig. 1). Especialmente significativa es su ausencia en aquellas construcciones más monumentales, como los tholoi de El Romeral (Antequera, Málaga), 


\begin{tabular}{|c|c|c|c|c|c|c|c|c|c|c|c|c|}
\hline 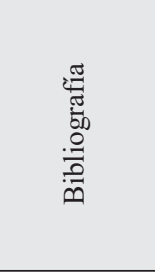 & 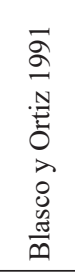 & 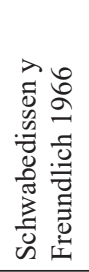 & 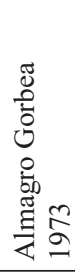 & 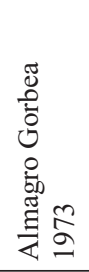 & | & 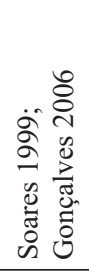 & $\begin{array}{l}\vec{\sigma} \\
\overline{\bar{N}} \\
\overrightarrow{0} \\
0 \\
\overrightarrow{0} \\
\overline{0} \\
\overrightarrow{0} \\
\overline{0}\end{array}$ & 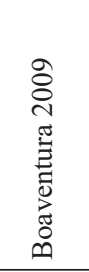 & 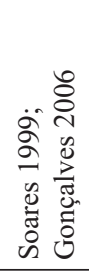 & 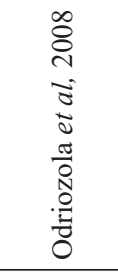 & 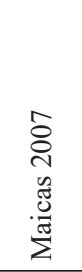 & 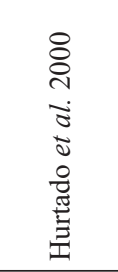 \\
\hline 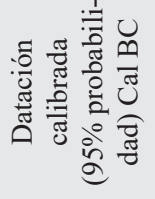 & 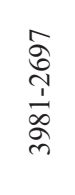 & 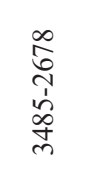 & 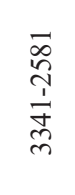 & 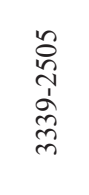 & 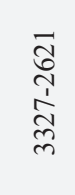 & 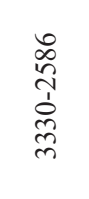 & 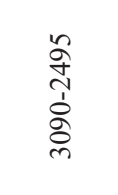 & 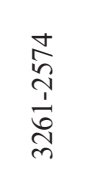 & 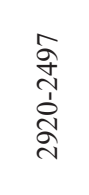 & 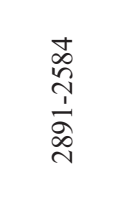 & 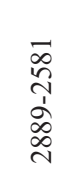 & 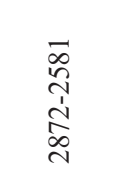 \\
\hline 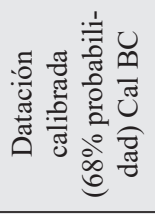 & 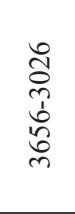 & $\begin{array}{l}\text { पे } \\
\text { के } \\
\text { ते } \\
\text { ते } \\
\text { ले }\end{array}$ & $\begin{array}{l}\text { Eิ } \\
\text { ì } \\
\hat{0} \\
\text { in }\end{array}$ & 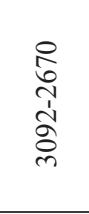 & $\begin{array}{l}\overrightarrow{\widetilde{d}} \\
\stackrel{i}{T} \\
\frac{\pi}{\pi}\end{array}$ & $\begin{array}{l}\text { के } \\
\text { 1े } \\
\text { oे } \\
\text { dे }\end{array}$ & $\begin{array}{l}\text { तु } \\
\text { ปे } \\
\text { ते }\end{array}$ & 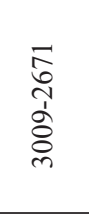 & 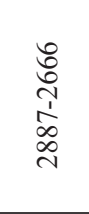 & 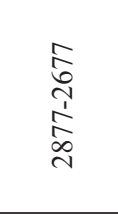 & 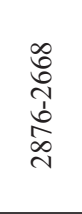 & 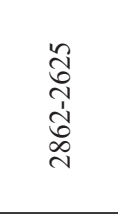 \\
\hline $\begin{array}{l}\overrightarrow{\tilde{n}} \\
\overrightarrow{\tilde{J}} \\
\vec{y}\end{array}$ & $\begin{array}{l}8 \\
\text { in } \\
+ \\
0 \\
0 \\
+\end{array}$ & 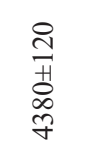 & 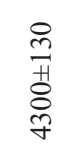 & 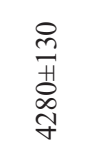 & $\begin{array}{l}\text { ๙े } \\
\text { ते } \\
\text { ๙े }\end{array}$ & \begin{tabular}{l}
$\frac{8}{1}$ \\
$\frac{1}{3}$ \\
\multirow{7}{\gamma}{}
\end{tabular} & $\begin{array}{l}8 \\
\frac{\Xi}{3} \\
\text { ปे } \\
\text { J }\end{array}$ & 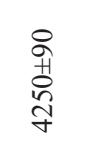 & $\begin{array}{l}\infty \\
0 \\
0 \\
\infty \\
\forall \\
\forall\end{array}$ & $\begin{array}{l}n \\
0 \\
0 \\
0 \\
\sigma \\
\forall\end{array}$ & $\begin{array}{l}8 \\
\text { 10 } \\
\text { o } \\
\Rightarrow\end{array}$ & 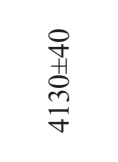 \\
\hline$\bigcup_{\substack{\infty \\
\infty}}^{8}$ & 1 & | & 1 & 1 & 1 & 1 & 1 & $\begin{array}{l}\text { त̃ } \\
\text { ồ }\end{array}$ & 1 & 1 & $\begin{array}{l}0 \\
\stackrel{0}{1}\end{array}$ & | \\
\hline 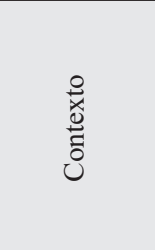 & 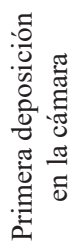 & | & 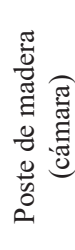 & 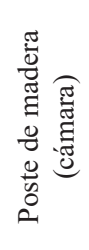 & \multirow{4}{*}{ 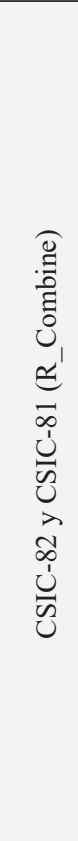 } & 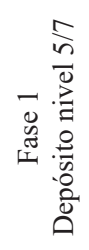 & 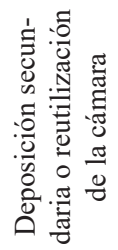 & | & 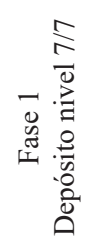 & 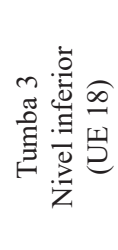 & 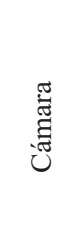 & 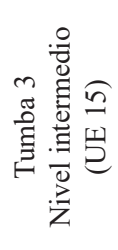 \\
\hline 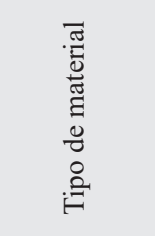 & 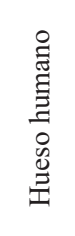 & 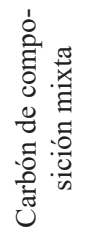 & 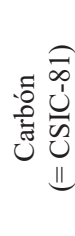 & 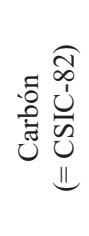 & & 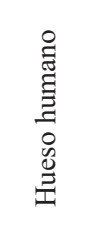 & 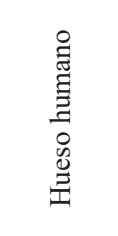 & 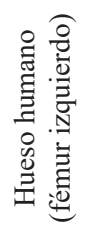 & 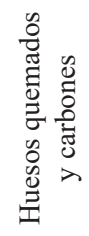 & 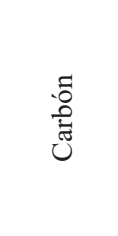 & 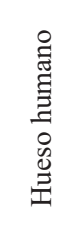 & 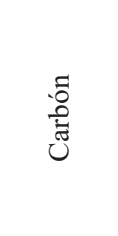 \\
\hline 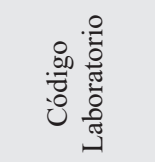 & 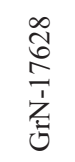 & $\underset{\underline{z}}{\stackrel{N}{z}}$ & $\begin{array}{l}\tilde{D} \\
\bigcup_{\tilde{U}} \\
\tilde{U}\end{array}$ & $\begin{array}{l}\vec{\infty} \\
\bigcup_{0}^{\prime} \\
\overrightarrow{0}\end{array}$ & & $\begin{array}{l}n \\
2 \\
i \\
z_{1}^{1} \\
0\end{array}$ & $\begin{array}{l}n \\
2 \\
\frac{2}{1} \\
\sum_{0}^{3}\end{array}$ & 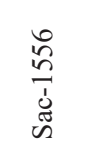 & 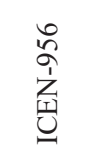 & 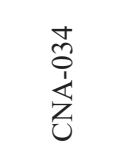 & | & 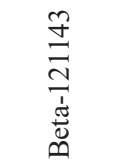 \\
\hline 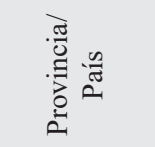 & 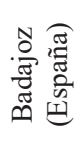 & 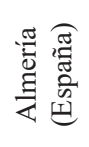 & 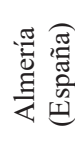 & 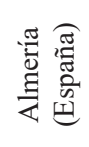 & & 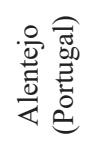 & 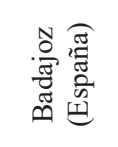 & 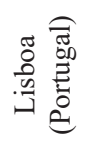 & 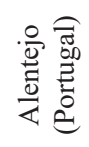 & 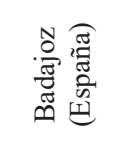 & 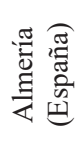 & 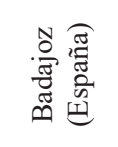 \\
\hline 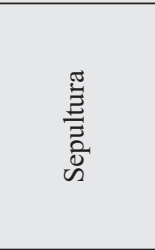 & 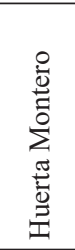 & 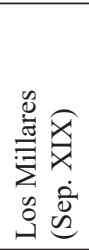 & 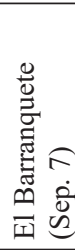 & 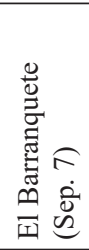 & 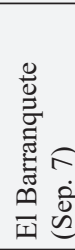 & 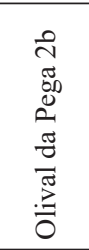 & 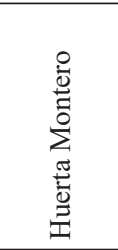 & 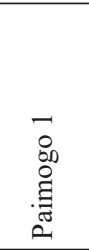 & 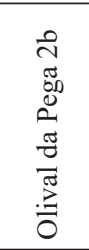 & 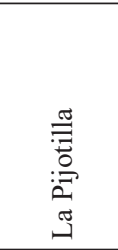 & 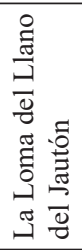 & 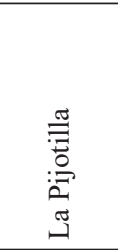 \\
\hline
\end{tabular}




\begin{tabular}{|c|c|c|c|c|c|c|c|c|c|c|c|}
\hline 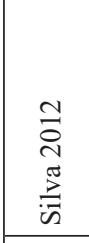 & 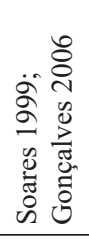 & 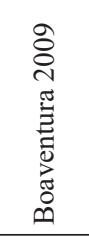 & 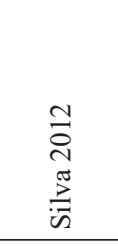 & 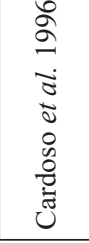 & 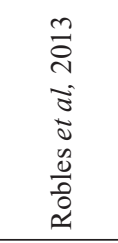 & 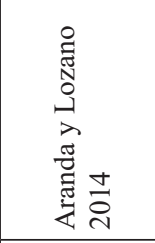 & 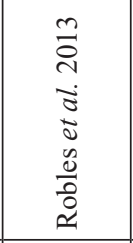 & 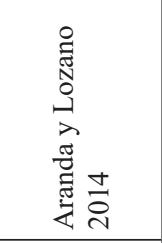 & 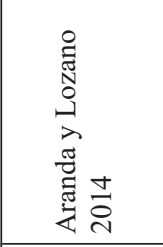 & 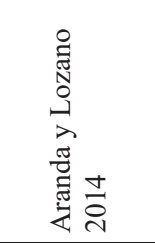 & 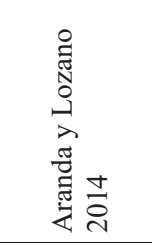 \\
\hline 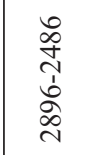 & $\begin{array}{l}\overrightarrow{0} \\
\vdots \\
i \\
\dot{1} \\
\infty \\
\infty \\
\stackrel{N}{N}\end{array}$ & 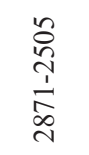 & 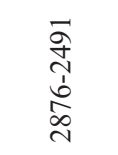 & 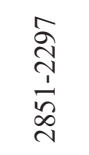 & $\begin{array}{l}\overline{\widehat{\lambda}} \\
\tilde{n} \\
\hat{n}\end{array}$ & 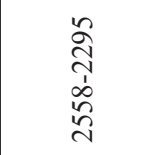 & 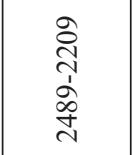 & 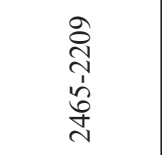 & $\begin{array}{l}\infty \\
\stackrel{్}{1} \\
\hat{\delta} \\
\stackrel{్}{1}\end{array}$ & 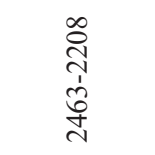 & 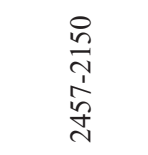 \\
\hline 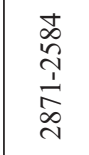 & 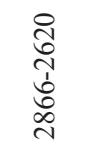 & 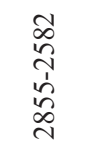 & 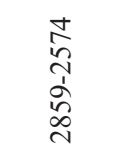 & 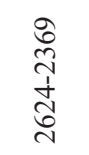 & \begin{tabular}{l}
0 \\
\multirow{1}{*}{} \\
$\infty$ \\
0 \\
$\hat{n}$ \\
\end{tabular} & 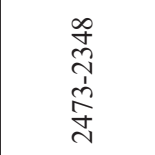 & 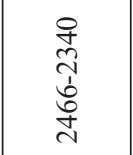 & 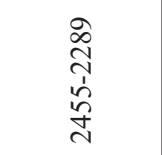 & 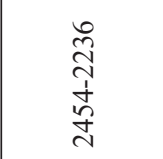 & 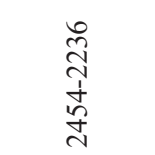 & 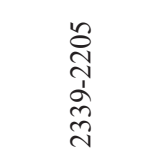 \\
\hline $\begin{array}{l}\stackrel{8}{8} \\
\text { के } \\
\stackrel{0}{7}\end{array}$ & $\begin{array}{l}8 \\
0 \\
01 \\
0 \\
\Rightarrow \\
7\end{array}$ & $\begin{array}{l}\stackrel{9}{+} \\
\stackrel{+}{*} \\
⿱ 亠 乂\end{array}$ & 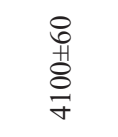 & 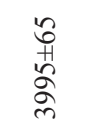 & $\begin{array}{l}\text { in } \\
\text { के } \\
\text { के } \\
\text { m }\end{array}$ & 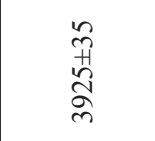 & $\begin{array}{l}\text { i } \\
\text { 蒿 } \\
\text { के }\end{array}$ & $\begin{array}{l}n \\
\dddot{m} \\
0 \\
\infty \\
m \\
m\end{array}$ & $\begin{array}{l}\sim \\
\stackrel{n}{0} \\
\stackrel{0}{0} \\
\infty \\
n\end{array}$ & $\begin{array}{l}n \\
0 \\
0 \\
0 \\
0 \\
n\end{array}$ & 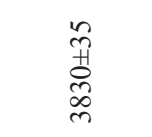 \\
\hline & 1 & : & 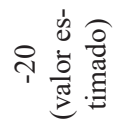 & | & $\begin{array}{l}\text { तै } \\
\text { ڤิ }\end{array}$ & 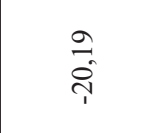 & $\begin{array}{l}\infty \\
\stackrel{\infty}{1}\end{array}$ & $\overrightarrow{\hat{\imath}}$ & $\frac{\hat{O}}{\hat{T}}$ & 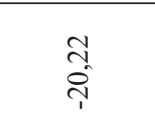 & $\begin{array}{l}0 \\
\frac{0}{1} \\
\frac{1}{1}\end{array}$ \\
\hline & 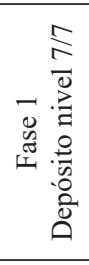 & I & 1 & 1 & 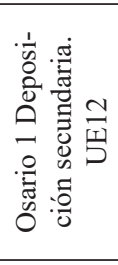 & $\begin{array}{l}\geq \\
\stackrel{D}{z}\end{array}$ & 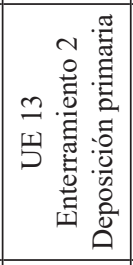 & $\begin{array}{l}\geq \\
\stackrel{0}{z}\end{array}$ & $\begin{array}{l}Z \\
\stackrel{\vec{D}}{z}\end{array}$ & $\frac{Z}{\bar{D}}$ & $\begin{array}{l}\geq \\
\stackrel{D}{z}\end{array}$ \\
\hline 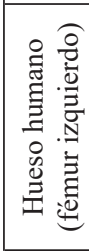 & 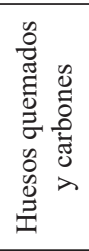 & 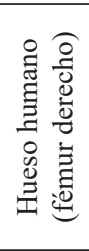 & 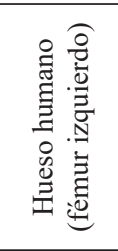 & | & 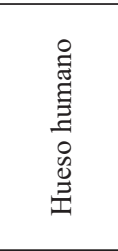 & 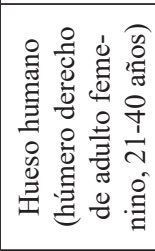 & 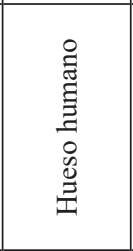 & 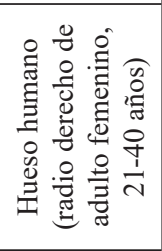 & 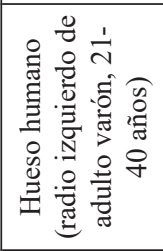 & 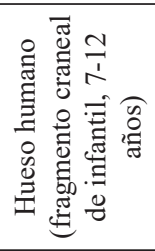 & 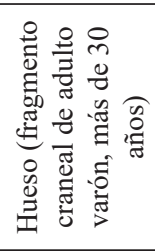 \\
\hline 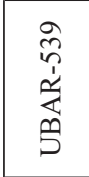 & $\begin{array}{l}\hat{n} \\
\hat{i} \\
z_{0} \\
\underline{0}\end{array}$ & 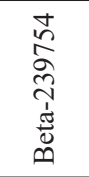 & 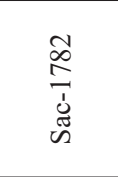 & 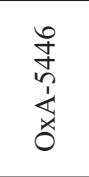 & $\begin{array}{l}\overline{\hat{~}} \\
\tilde{\tilde{d}} \\
\tilde{n}\end{array}$ & 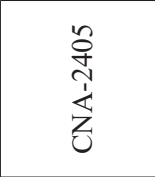 & 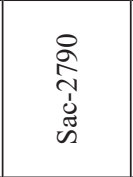 & 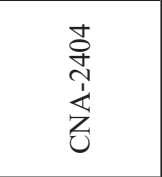 & 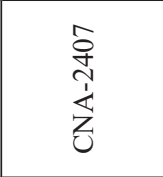 & 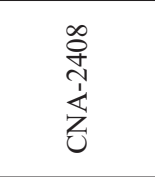 & 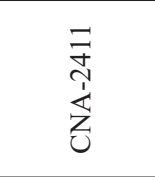 \\
\hline 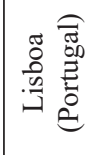 & 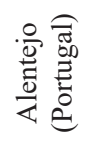 & 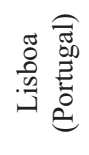 & 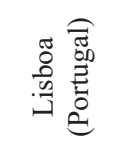 & 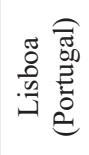 & 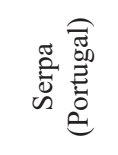 & 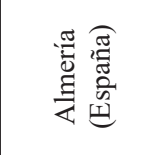 & 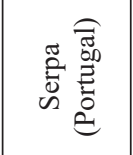 & 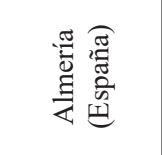 & 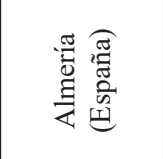 & 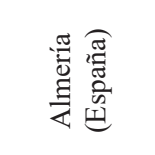 & 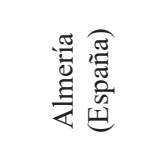 \\
\hline $\begin{array}{l}\text { : } \\
\text { 品 } \\
\text { 埡 }\end{array}$ & 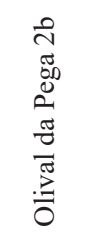 & 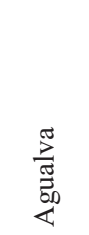 & 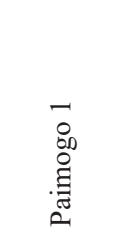 & 䄊 & 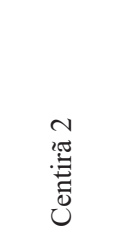 & 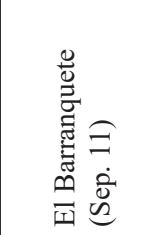 & 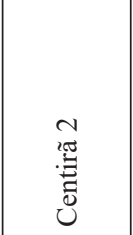 & 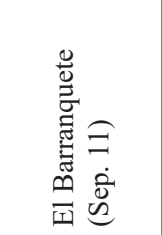 & 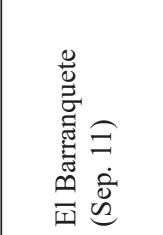 & 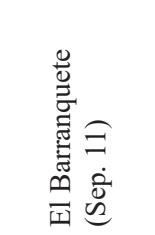 & 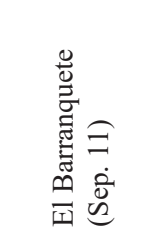 \\
\hline
\end{tabular}




\begin{tabular}{|c|c|c|c|c|c|c|c|c|c|}
\hline 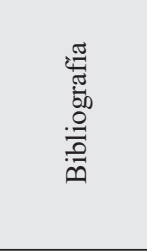 & 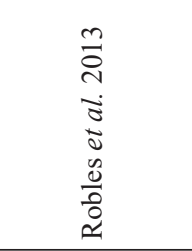 & 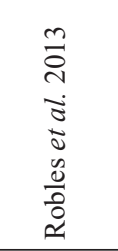 & 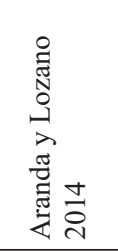 & 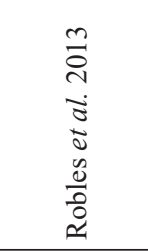 & 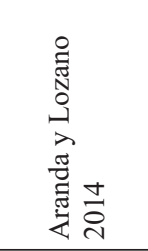 & 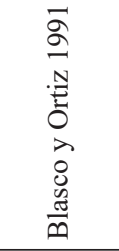 & 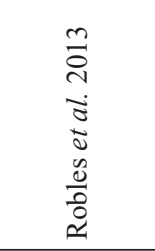 & 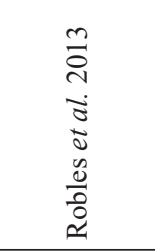 & | \\
\hline 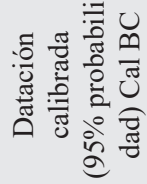 & 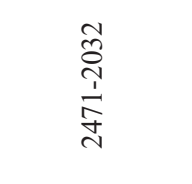 & 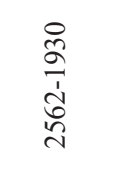 & $\begin{array}{l}\overrightarrow{\widetilde{े}} \\
\text { ळे } \\
\text { ते }\end{array}$ & 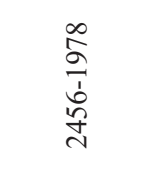 & 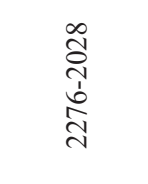 & $\begin{array}{l}\infty \\
\infty \\
\infty \\
\infty \\
\infty \\
\stackrel{1}{+1}\end{array}$ & 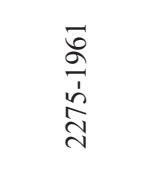 & 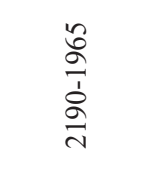 & $\frac{\infty}{\frac{\infty}{1}}$ \\
\hline 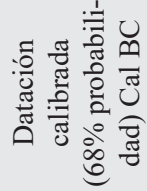 & 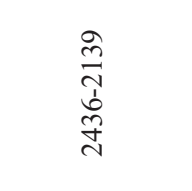 & \begin{tabular}{l} 
Ĩ \\
$\stackrel{1}{1}$ \\
$o$ \\
\multirow{2}{*}{} \\
d
\end{tabular} & 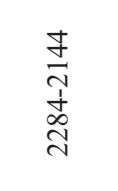 & 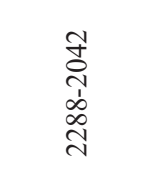 & 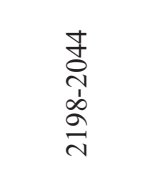 & 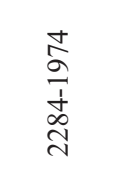 & $\begin{array}{l}\infty \\
\hat{O} \\
\dot{T} \\
\stackrel{2}{N}\end{array}$ & 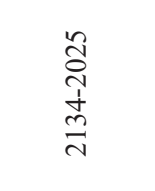 & $\begin{array}{l}\text { ڤે̀ } \\
\hat{N} \\
\stackrel{\sim}{N}\end{array}$ \\
\hline 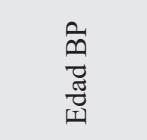 & $\begin{array}{l}\infty \\
\infty \\
+1 \\
\infty \\
\infty \\
\infty\end{array}$ & $\begin{array}{l}\stackrel{0}{7} \\
\text { 菅 } \\
\text { 品 }\end{array}$ & 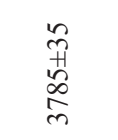 & $\begin{array}{l}0 \\
\text { 草 } \\
0 \\
0\end{array}$ & 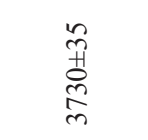 & 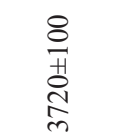 & $\underset{m}{\stackrel{n}{+}}$ & 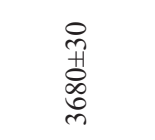 & 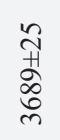 \\
\hline$\underbrace{}_{\substack{0 \\
0}}$ & $\begin{array}{l}\infty \\
\stackrel{\leftrightarrow}{1}\end{array}$ & ণิ & ๙ิ) & $\overrightarrow{\stackrel{\Upsilon}{1}}$ & $\begin{array}{l}\stackrel{0}{0} \\
\infty \\
\infty\end{array}$ & I & ڤิ & $\stackrel{\overbrace{}}{1}$ & | \\
\hline 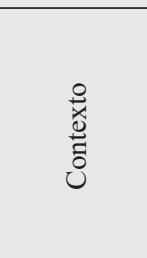 & 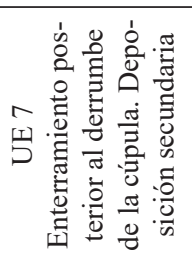 & 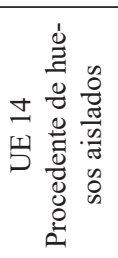 & $\begin{array}{l}\geq \\
\stackrel{\vec{D}}{z} \\
z\end{array}$ & 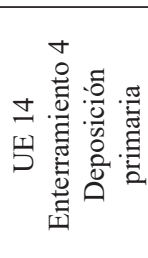 & $\begin{array}{l}\geq \\
\stackrel{\vec{D}}{Z} \\
\dot{z}\end{array}$ & 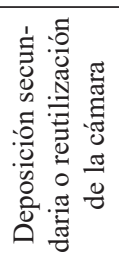 & 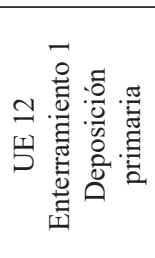 & 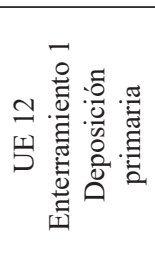 & $\stackrel{9}{\Xi}$ \\
\hline 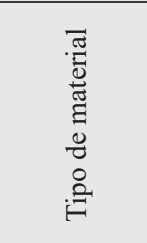 & 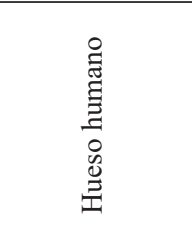 & 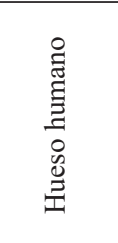 & 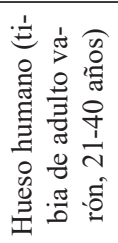 & 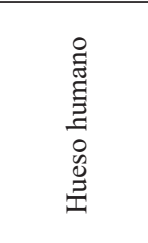 & 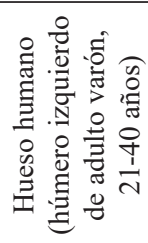 & 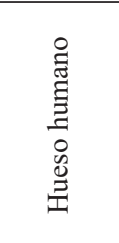 & 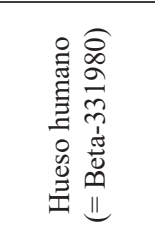 & 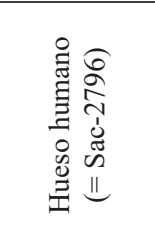 & 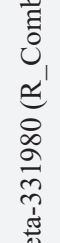 \\
\hline 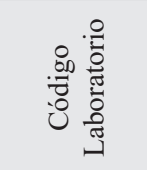 & 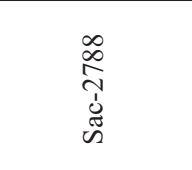 & $\begin{array}{l}\widetilde{\Lambda} \\
\hat{\tilde{J}} \\
\tilde{n}\end{array}$ & 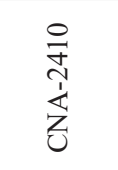 & 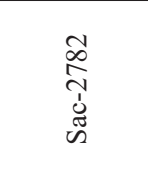 & 亲 & 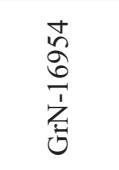 & 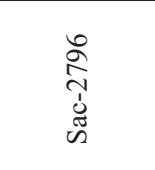 & 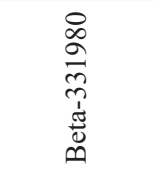 & 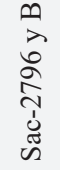 \\
\hline 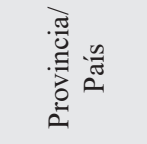 & 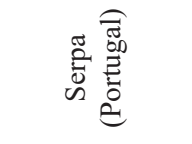 & 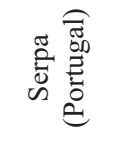 & $\begin{array}{l}\text { 莺 } \\
\text { 焉 } \\
\text { 量 }\end{array}$ & 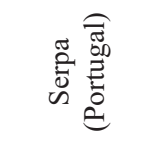 & 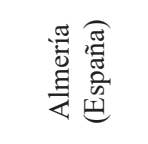 & 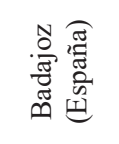 & 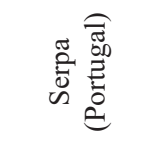 & 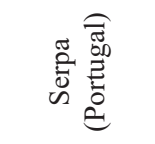 & \\
\hline 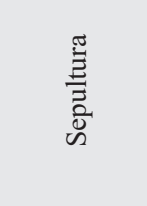 & 苞 & שֶ & 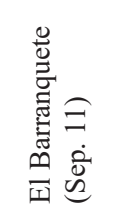 & 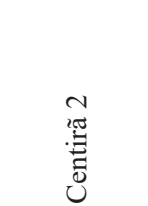 & 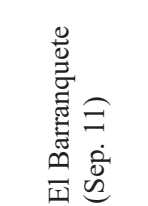 & 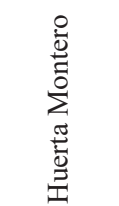 & 苞 & 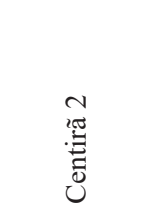 & $\begin{array}{l}\text { 营 } \\
\text { है }\end{array}$ \\
\hline
\end{tabular}


LA TEMPORALIDAD DE LAS SEPULTURAS MEGALÍTICAS TIPO THOLOS DEL SUR DE LA PENÍNSULA...

\begin{tabular}{|c|c|c|c|c|c|c|c|c|c|}
\hline 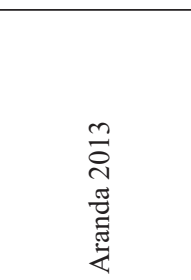 & 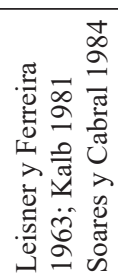 & 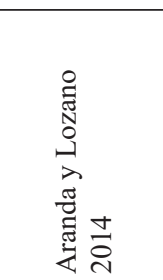 & 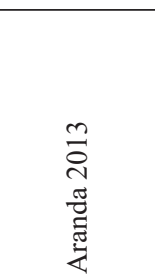 & 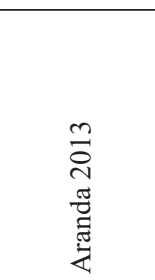 & 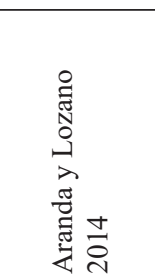 & 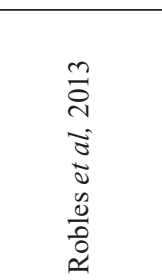 & $\begin{array}{l}\infty \\
\stackrel{5}{a} \\
\vdots \\
\vdots \\
\vdots \\
0 \\
0 \\
0 \\
0 \\
0 \\
\end{array}$ & 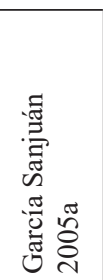 & 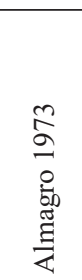 \\
\hline $\begin{array}{l}\frac{\partial}{\sigma} \\
\frac{\hat{n}}{2}\end{array}$ & $\begin{array}{l}\overrightarrow{\tilde{\infty}} \\
\frac{\infty}{1} \\
\text { ते }\end{array}$ & $\begin{array}{l}\infty \\
\infty \\
\frac{\infty}{1} \\
\stackrel{\sim}{1}\end{array}$ & 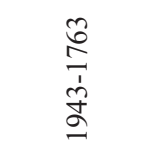 & 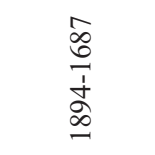 & $\begin{array}{l}\mathscr{0} \\
\stackrel{1}{1} \\
\stackrel{d}{a}\end{array}$ & 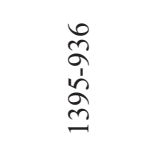 & 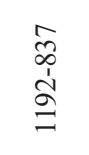 & 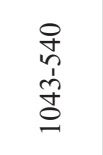 & \begin{tabular}{l}
$\stackrel{I}{7}$ \\
\multirow{\infty}{*}{} \\
$\stackrel{\infty}{\infty}$
\end{tabular} \\
\hline $\begin{array}{l}\stackrel{a}{a} \\
\frac{1}{d} \\
\frac{1}{1}\end{array}$ & $\frac{\stackrel{0}{2}}{\frac{1}{1}}$ & $\frac{\infty}{\tilde{\sigma}}$ & 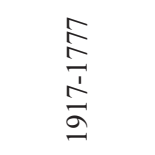 & $\begin{array}{l}\mathfrak{Q} \\
\stackrel{1}{1} \\
\infty \\
\infty \\
0\end{array}$ & 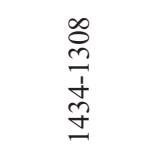 & 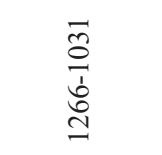 & $\begin{array}{l}\stackrel{8}{a} \\
\text { ì } \\
\vdots \\
0\end{array}$ & $\frac{8}{\stackrel{8}{1}}$ & $\begin{array}{l}\vec{f} \\
1 \\
\vdots \\
\infty \\
\infty\end{array}$ \\
\hline $\begin{array}{l}\text { } \\
\text { 苦 } \\
\text { 品 }\end{array}$ & $\begin{array}{l}\text { o } \\
\text { 웅 } \\
\text { d }\end{array}$ & 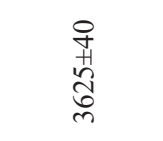 & $\begin{array}{l}0 \\
\stackrel{\pi}{*} \\
0 \\
心 \\
n\end{array}$ & $\begin{array}{l}\text { P } \\
\text { 草 } \\
\text { 帛 }\end{array}$ & 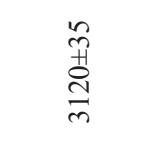 & 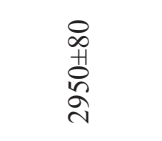 & 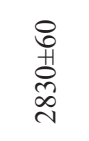 & 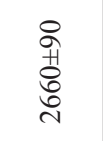 & $\begin{array}{l}\frac{8}{0} \\
\frac{1}{0} \\
i \\
i\end{array}$ \\
\hline$\stackrel{\widehat{\infty}}{\rightarrow}$ & | & 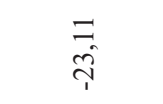 & $\begin{array}{l}\stackrel{m}{2} \\
\stackrel{2}{1}\end{array}$ & $\stackrel{+}{\infty}$ & $\begin{array}{l}\infty \\
\stackrel{0}{\nearrow}\end{array}$ & $\stackrel{\text { }}{\hat{\imath}}$ & | & 1 & 1 \\
\hline $\begin{array}{l}\Xi \\
\stackrel{\vec{D}}{\vec{z}} \\
\dot{z}\end{array}$ & 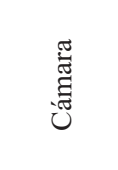 & $\begin{array}{l}\text { 目 } \\
\stackrel{\vec{\partial}}{\mathrm{z}}\end{array}$ & $\begin{array}{l}\text { 目 } \\
\stackrel{\vec{\partial}}{\mathrm{Z}}\end{array}$ & $\begin{array}{l}\exists \\
\stackrel{\vec{D}}{Z} \\
\stackrel{z}{Z}\end{array}$ & $\begin{array}{l}\exists \\
\stackrel{\vec{D}}{Z} \\
\stackrel{z}{Z}\end{array}$ & 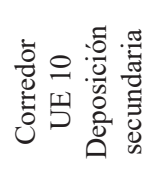 & 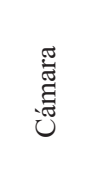 & 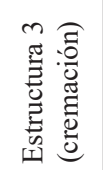 & 1 \\
\hline 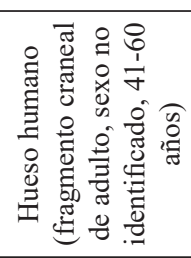 & 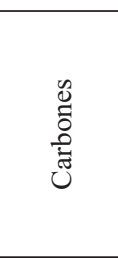 & 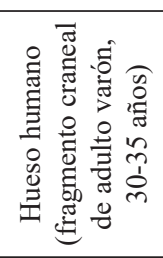 & 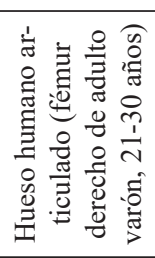 & 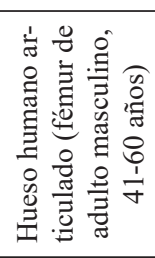 & 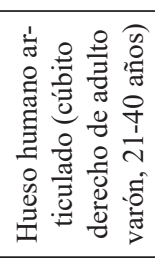 & 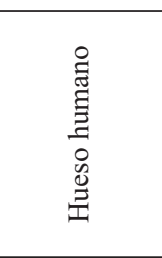 & 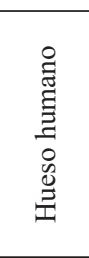 & 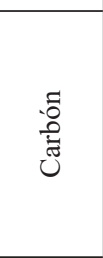 & 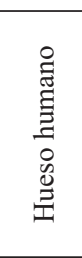 \\
\hline 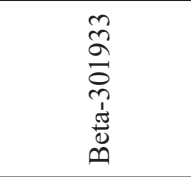 & 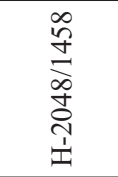 & 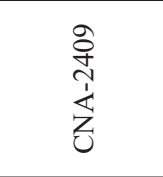 & 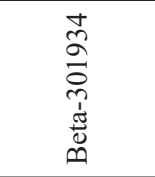 & 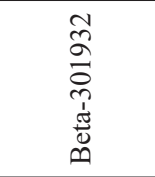 & 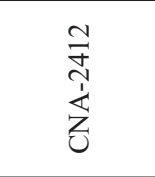 & 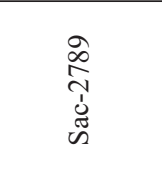 & 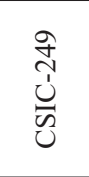 & $\begin{array}{l}\tilde{N} \\
\tilde{n} \\
0 \\
\frac{1}{\pi} \\
\infty \\
\infty\end{array}$ & 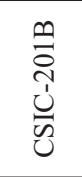 \\
\hline 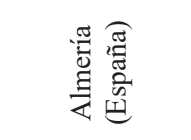 & 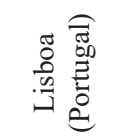 & 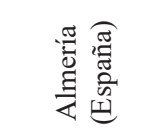 & 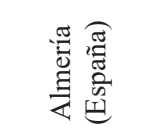 & 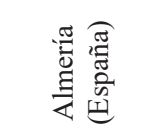 & 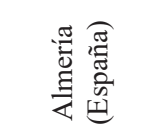 & 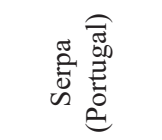 & 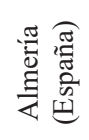 & 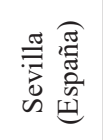 & 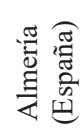 \\
\hline 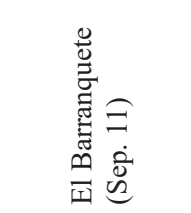 & 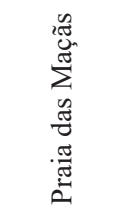 & 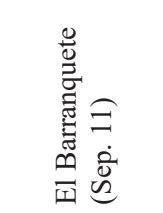 & 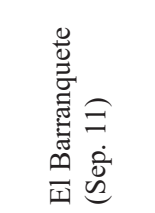 & 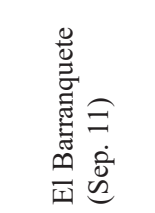 & 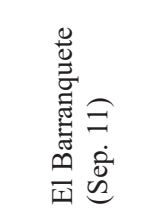 & 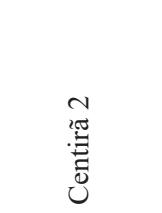 & 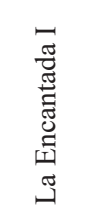 & 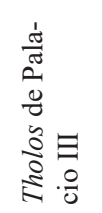 & 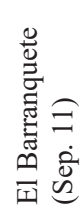 \\
\hline
\end{tabular}


La Pastora o Matarrubilla (Valencina de la Concepción, Sevilla). En realidad, de las 41 dataciones 21 se concentran en sólo dos sepulturas: la número 11 de la necrópolis de El Barranquete (Níjar, Almería) con 13 dataciones (Aranda y Lozano 2014) y la tumba 2 de Centirã con ocho (Brinches, Serpa) (Robles et al. 2013). Esta importante concentración debe relacionarse con el cambio que actualmente se está produciendo en las estrategias de datación. Frente a la tradicional situación donde las sepulturas quedaban fechadas en el mejor de los casos con dos o tres dataciones, ahora han comenzado a realizarse amplias series radiométricas con las que definir con mayor precisión la temporalidad de estos monumentos. Este sería el caso de la sepultura 11 de El Barranquete, para la que se ha fechado el número mínimo de individuos identificados en el estudio antropológico (Aranda y Lozano 2014).

El reciente incremento del número de dataciones ha tenido también un efecto positivo, ya que la mayoría se han realizado sobre hueso humano (31 dataciones). Este hecho posee dos grandes ventajas. En primer lugar, se trata de muestras de "vida corta", lo que asegura que no hay distancia temporal entre el inicio de la descomposición del isótopo $\mathrm{C} 14$ y el acontecimiento que se data, la muerte del individuo. En segundo lugar, la datación de restos antropológicos ha permitido fechar prácticas funerarias inimaginables si sólo se hubieran tenido en cuenta la tipología de los ajuares funerarios asociados o las características arquitectónicas de las sepulturas (Lorrio y Montero 2004; García Sanjuán 2005a, 2011; Aranda 2013, 2015; Aranda y Lozano 2014).

El número de dataciones realizadas sobre muestras de vida larga (carbón indeterminado) es, por tanto, reducido (siete), lo que minimiza la incertidumbre del denominado efecto "madera vieja". No obstante, en dos casos la datación se ha realizado sobre muestras que mezclan carbones con huesos quemados, una mala práctica dado que la fecha obtenida no es representativa de ningún acontecimiento significativo desde una perspectiva arqueológica. Se trata de las fechas ICEN-956 e ICEN-957, pertenecientes a la sepultura Olival da Pega 2b (Alentejo, Portugal) (Soares 1999; Gonçalves 2006). Otra debilidad de la serie radiométrica son aquellas dataciones con amplias desviaciones típicas de \pm 100 años o superiores (un caso excepcional es la fecha GrN-17628 de Huerta Montero, con una desviación de \pm 250 años). Aunque son pocos casos (nueve), sus extensos intervalos de probabilidad hacen que la utilidad cronológica de estas dataciones sea muy relativa.
A partir de las características que posee la serie radiométrica de los tholoi del sur peninsular, se ha procedido a su valoración utilizando diferentes procedimientos estadísticos. En primer lugar, las 41 dataciones radiocarbónicas han sido analizadas mediante la estadística Bayesiana, que permite reducir los intervalos de probabilidad combinando la cronología absoluta con otras formas de información cronológica como, por ejemplo, la secuenciación estratigráfica. Además, esta técnica permite crear nuevos intervalos de probabilidad para el comienzo y final (Boundary) de las diferentes fases o eventos en los que las dataciones son agrupadas, así como medir en número de años la duración de cada fase (Bronk Ramsey 1995; Bayliss et al. 2007).

Para el caso que nos ocupa no es posible establecer una secuenciación interna de las dataciones, por lo que todas ellas han sido consideradas como una sola fase asumiendo una distribución interna uniforme. El modelo cronológico resultante (fig. 2 y tabla 2), aunque no supone una reducción de los intervalos de probabilidad de cada datación, exceptuando las que se sitúan en los extremos de la fase, sí que proporciona unas estimaciones para el comienzo y final de este fenómeno así como de su duración. De esta forma, el inicio de este nuevo tipo de sepulturas megalíticas se produciría entre el 3211-2837 cal BC (95\% de probabilidad), muy probablemente en la transición entre el IV y III milenios (3070-2900 cal BC al 68\% de probabilidad). La estimación cronológica para las últimas prácticas rituales sería en torno al 980-576 cal BC (95\% de probabilidad), lo que posiblemente ocurrió entre los siglos IX-VIII cal BC (890-710 cal BC al 68\% de probabilidad), coincidiendo con el final de la Edad del Bronce. La duración en número de años se sitúa entre el 2000-2213 años (68\% de probabilidad) o entre 1892-2347 años (95\% probabilidad).

En cuanto a la distribución interna de las dataciones, esta se caracteriza por su continuidad a lo largo del III y II milenios con un posible hiatus a mediados del II milenio (fig. 3). Aunque el número de dataciones disponibles hace que cualquier valoración deba ser considerada como tentativa, es muy sugerente la coincidencia de este hiatus con la crisis de la sociedades argáricas (c 1550 cal BC) que supuso su desaparición (Aranda et al. 2015). La serie radiocarbónica presenta, además, dos importantes concentraciones de dataciones (fig. 3), una primera en la Edad del Cobre precampaniforme coincidiendo con la consolidación de la nueva arquitectura megalítica y la segunda a partir del 2500 cal BC prolongándose durante el Bronce Antiguo y Pleno. Durante este último y extenso periodo 


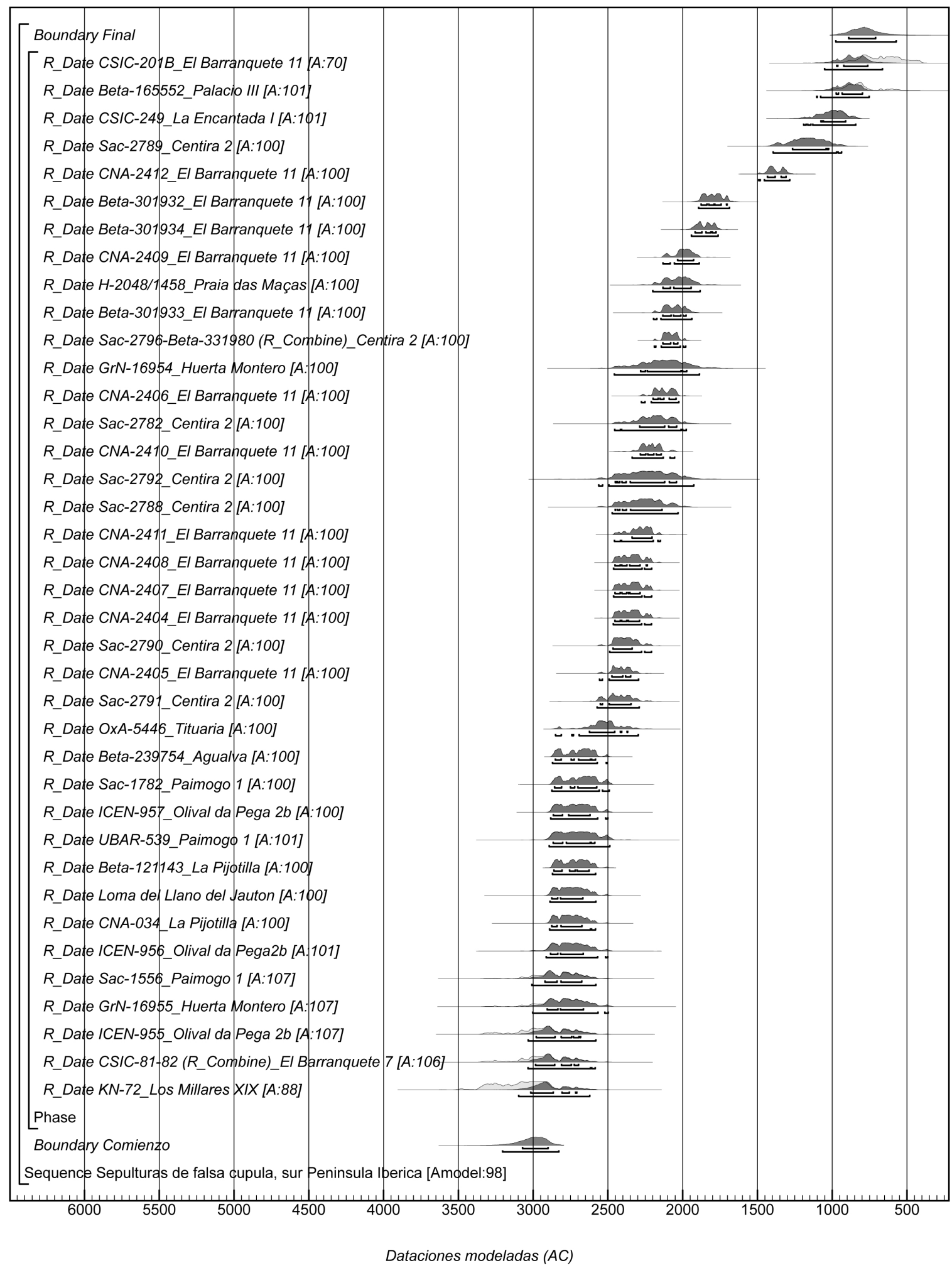

Figura 2. Modelo bayesiano de las sepulturas tipo tholos del sur de la península ibérica. Se ha utilizado el software OxCal (v.4.2) (Bronk Ramsey 2009). 
Tabla 2. Dataciones radiocarbónicas y estimaciones probabilísticas del modelo bayesiano aplicado a las sepulturas tipo tholos.

\begin{tabular}{|c|c|c|c|c|c|}
\hline Sepultura & $\begin{array}{c}\text { Código } \\
\text { Laboratorio }\end{array}$ & Edad BP & $\begin{array}{c}\text { Datación calibrada } \\
\text { (95\% probabilidad) } \\
\text { Cal BC }\end{array}$ & $\begin{array}{l}\text { Posterior density } \\
\text { estimate } \\
(68 \%) \text { cal BC }\end{array}$ & $\begin{array}{c}\text { Posterior density } \\
\text { estimate } \\
(95 \%) \text { cal BC }\end{array}$ \\
\hline Los Millares (Sep. XIX) & $\mathrm{KN}-72$ & $4380 \pm 120$ & $3485-2678$ & $3018-2709$ & $3097-2621$ \\
\hline El Barranquete (Sep. 7) & $\begin{array}{l}\text { R_Combine } \\
\text { CSIC- } 82 \text { y } \\
\text { CSIC- } 81\end{array}$ & $4290 \pm 92$ & $3327-2621$ & $2979-2696$ & $3035-2585$ \\
\hline Olival da Pega 2b & ICEN-955 & $4290 \pm 100$ & $3330-2586$ & $2976-2693$ & $3034-2581$ \\
\hline Huerta Montero & GrN-16955 & $4220 \pm 100$ & $3090-2495$ & 2906-2640 & 3006-2499 \\
\hline Paimogo 1 & Sac-1556 & $4250 \pm 90$ & $3261-2574$ & $2921-2677$ & $3008-2582$ \\
\hline Olival da Pega $2 b$ & ICEN-956 & $4180 \pm 80$ & $2920-2497$ & $2885-2666$ & 2914-2501 \\
\hline La Pijotilla & CNA-034 & $4168 \pm 55$ & $2891-2584$ & $2876-2676$ & $2890-2584$ \\
\hline La Loma del Llano del Jautón & - & $4160 \pm 60$ & $2889-2581$ & $2874-2668$ & $2887-2581$ \\
\hline La Pijotilla & Beta-121143 & $4130 \pm 40$ & $2872-2581$ & $2861-2626$ & $2871-2583$ \\
\hline Paimogo 1 & UBAR-539 & $4130 \pm 90$ & 2896-2486 & $2866-2584$ & $2893-2487$ \\
\hline Olival da Pega 2b & ICEN-957 & $4130 \pm 60$ & 2884-2501 & 2864-2620 & $2883-2501$ \\
\hline Agualva & Beta-239754 & $4110 \pm 40$ & 2871-2505 & $2858-2574$ & $2871-2505$ \\
\hline Paimogo 1 & Sac-1782 & $4100 \pm 60$ & 2876-2491 & $2853-2583$ & $2875-2491$ \\
\hline Tituaria & OxA-5446 & $3995 \pm 65$ & 2851-2297 & $2625-2368$ & $2850-2297$ \\
\hline Centirã 2 & Sac-2791 & $3940 \pm 50$ & 2573-2291 & $2554-2346$ & 2573-2291 \\
\hline El Barranquete (Sep. 11) & CNA-2405 & $3925 \pm 35$ & $2558-2295$ & $2473-2348$ & $2555-2295$ \\
\hline Centirã 2 & Sac-2790 & $3900 \pm 45$ & 2489-2209 & $2466-2339$ & 2488-2209 \\
\hline El Barranquete (Sep. 11) & CNA-2404 & $3865 \pm 35$ & 2465-2209 & 2454-2289 & $2465-2209$ \\
\hline El Barranquete (Sep. 11) & CNA-2407 & $3860 \pm 35$ & 2463-2208 & 2453-2286 & 2463-2208 \\
\hline El Barranquete (Sep. 11) & CNA-2408 & $3860 \pm 35$ & 2463-2208 & $2454-2240$ & 2463-2208 \\
\hline El Barranquete (Sep. 11) & CNA-2411 & $3830 \pm 35$ & $2457-2150$ & 2339-2205 & $2457-2150$ \\
\hline Centirã 2 & Sac-2788 & $3810 \pm 80$ & 2471-2032 & $2436-2139$ & $2472-2032$ \\
\hline Centirã 2 & Sac-2792 & $3790 \pm 110$ & $2562-1930$ & $2450-2042$ & 2561-1926 \\
\hline El Barranquete (Sep. 11) & CNA-2410 & $3785 \pm 35$ & 2339-2051 & $2283-2145$ & 2339-2055 \\
\hline Centirã 2 & Sac-2782 & $3760 \pm 70$ & 2456-1978 & $2288-2042$ & $2456-1977$ \\
\hline El Barranquete (Sep. 11) & CNA-2406 & $3730 \pm 35$ & 2276-2028 & $2198-2045$ & $2276-2027$ \\
\hline Huerta Montero & GrN-16954 & $3720 \pm 100$ & 2458-1889 & $2281-1976$ & $2458-1889$ \\
\hline Centirã 2 & $\begin{array}{c}\text { R_Combine } \\
\text { Sac-2796 y } \\
\text { Beta-331980 }\end{array}$ & $3689 \pm 25$ & $2191-1980$ & $2133-2033$ & $2191-1980$ \\
\hline El Barranquete (Sep. 11) & Beta-301933 & $3670 \pm 40$ & 2195-1939 & 2134-1978 & 2195-1939 \\
\hline Praia das Maçãs & $\mathrm{H}-2048 / 1458$ & $3640 \pm 60$ & $2200-1831$ & $2132-1942$ & $2200-1884$ \\
\hline El Barranquete (Sep. 11) & CNA-2409 & $3625 \pm 40$ & 2132-1889 & 2034-1928 & $2132-1889$ \\
\hline El Barranquete (Sep. 11) & Beta-301934 & $3530 \pm 30$ & $1943-1763$ & $1917-1777$ & $1942-1764$ \\
\hline El Barranquete (Sep. 11) & Beta-301932 & $3470 \pm 40$ & 1894-1687 & $1878-1704$ & 1894-1687 \\
\hline El Barranquete (Sep. 11) & CNA-2412 & $3120 \pm 35$ & 1492-1285 & 1434-1309 & $1492-1285$ \\
\hline Centirã 2 & Sac-2789 & $2950 \pm 80$ & $1395-936$ & $1270-1039$ & $1395-938$ \\
\hline La Encantada I & CSIC-249 & $2830 \pm 60$ & $1192-837$ & $1080-910$ & $1192-844$ \\
\hline Tholos de Palacio III & Beta-165552 & $2660 \pm 90$ & $1043-540$ & 974-798 & $1087-755$ \\
\hline El Barranquete (Sep. 11) & CSIC-201B & $2570 \pm 100$ & $898-412$ & $971-763$ & $1052-665$ \\
\hline
\end{tabular}


Figura 3. Suma de probabilidades de las dataciones radiocarbónicas de las sepulturas tipo tholos del sur de la península ibérica.

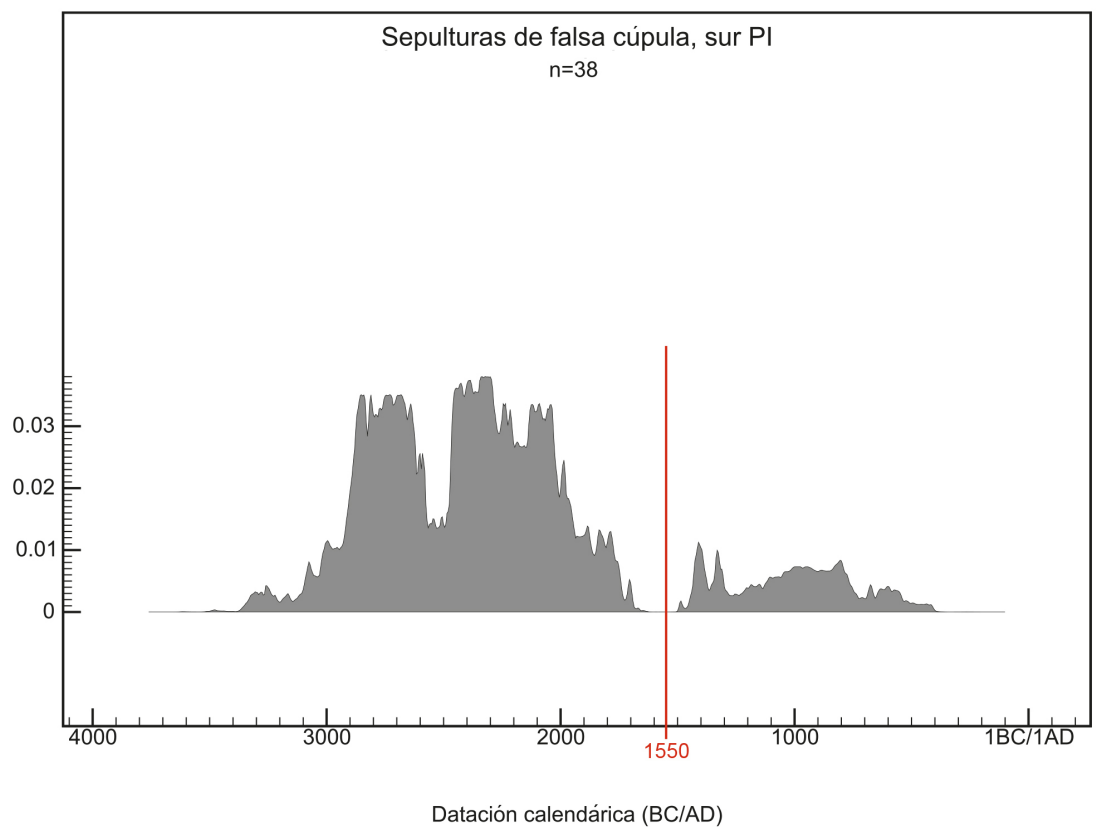

(c 2500-1550 cal BC) se produciría una intensa utilización funeraria de los tholoi sin que puedan establecerse diferenciaciones internas. Tras el posible hiatus de mediados del II milenio se constata una reutilización más atenuada, pero constante durante el Bronce Tardío y Final.

La concentración del $51 \%$ de las dataciones en sólo dos sepulturas, El Barranquete 11 y Centirã 2, permite comparar dos amplias series radiocarbónicas de 13 y 8 dataciones respectivamente realizadas sobre restos antropológicos. Ambas secuencias han sido tratadas mediante modelado bayesiano, a partir de la secuenciación de sus inhumaciones en dos grandes fases: niveles IV y III-II para El Barranquete (Aranda y Lozano 2014) y utilización funeraria anterior al derrumbe de la falsa cúpula y posterior a ella para Centirã 2 (Robles et al. 2013).

Sorprende que a pesar de tratarse de sepulturas localizadas en los extremos sureste y suroeste peninsulares, y por tanto separadas por cientos de kilómetros, presentan enormes semejanzas en su temporalidad (tabla 3). En ambos casos el inicio de las prácticas funerarias se produce en fechas similares: en Centirã 2 entre el 2525-2334 cal BC (68\% de probabilidad) y en El Barranquete 11 entre el 2452-2317 cal BC (68 $\%$ de probabilidad). Se trata de cronologías muy avanzadas dentro de la Edad del Cobre y alejadas de las fechas más antiguas de este tipo de construcciones monumentales.
Tabla 3. Estimaciones probabilísticas del comienzo y final de los modelos bayesianos de Centirã 2 (Robles et al. 2013) y la sepultura 11 de El Barranquete (Aranda y Lozano 2014)

\begin{tabular}{|c|c|c|c|}
\hline \multirow{4}{*}{ Centirã 2} & \multirow{2}{*}{$\begin{array}{l}\text { Fase I } \\
\text { (Anterior } \\
\text { derrumbe } \\
\text { cúpula) }\end{array}$} & Comienzo & $\begin{array}{c}2525-2334 \\
\text { cal BC (68\%) } \\
2682-2217 \\
\text { cal BC }(95 \%)\end{array}$ \\
\hline & & Final & $\begin{array}{c}2179-2046 \\
\text { cal BC }(68 \%) \\
2193-2003 \\
\text { cal BC }(95 \%)\end{array}$ \\
\hline & \multirow[b]{2}{*}{$\begin{array}{l}\text { Fase II } \\
\text { (Posterior } \\
\text { derrumbe } \\
\text { cúpula) }\end{array}$} & - & - \\
\hline & & Final & $\begin{array}{c}2143-1909 \\
\text { cal BC (68\%) } \\
2188-1518 \\
\text { cal BC }(95 \%)\end{array}$ \\
\hline \multirow{4}{*}{$\begin{array}{l}\text { EI Barran- } \\
\text { quete } 11\end{array}$} & \multirow{2}{*}{$\begin{array}{c}\text { Fase I } \\
\text { (Edad del } \\
\text { Cobre) }\end{array}$} & Comienzo & $\begin{array}{c}2452-2317 \\
\text { cal BC }(68 \%) \\
2555-2245 \\
\text { cal BC }(95 \%)\end{array}$ \\
\hline & & Final & $\begin{array}{c}2261-2137 \\
\operatorname{cal~BC~}(68 \%)\end{array}$ \\
\hline & \multirow{2}{*}{$\begin{array}{c}\text { Fase II } \\
\text { (Edad } \\
\text { del Bronce) }\end{array}$} & Comienzo & $\begin{array}{c}2154-2022 \\
\text { cal BC }(68 \%) \\
2218-1974 \\
\text { cal BC }(95 \%)\end{array}$ \\
\hline & & Final & $\begin{array}{c}1429-1240 \\
\text { cal BC }(68 \%) \\
1493-996 \\
\text { cal BC }(95 \%)\end{array}$ \\
\hline
\end{tabular}


Otra importante coincidencia es la continuidad y reutilización de ambas sepulturas durante la Edad del Bronce. En el caso de El Barranquete 11 se documenta una intensa continuidad en la utilización funeraria de la sepultura durante el Bronce Antiguo y Pleno, periodo paralelo al desarrollo de las sociedades argáricas ( $c$. 2200-1550 cal BC). Con posterioridad la tumba vuelve de nuevo a reutilizarse durante la segunda mitad de II milenio, pero ya sin la intensidad previa. El tholos de Centirã 2 mantiene igualmente una importante continuidad ritual durante el Bronce Antiguo, con al menos una reutilización posterior durante el Bronce Final.

\section{CONCLUSIONES}

A partir del análisis de la serie radiométrica de los tholoi del sur peninsular pueden establecerse diferentes valoraciones sobre la temporalidad de estas prácticas funerarias:

a) El inicio de este fenómeno se produciría muy probablemente en la transición entre el IV y III milenios (3070-2900 cal BC al 68\% de probabilidad). Si asumimos que las deposiciones funerarias más antiguas se realizaron inmediatamente después de la construcción de estas sepulturas, los primeros tholoi probablemente comenzaron a construirse en el último siglo del IV milenio. No parece que pueda establecerse una diferenciación temporal entre las diferentes comarcas del sur peninsular. Al menos esta es la situación que se documenta entre los extremos sureste y suroeste, donde se concentran las sepulturas con dataciones radiocarbónicas. Las fechas más antiguas de Los Millares XIX y El Barranquete 7 en Almería, Huerta Montero en Badajoz y Olival da Pega $2 b$ en el Alentejo portugués comparten el mismo intervalo de probabilidad según el modelado bayesiano (véase fig. 2 y tabla 2). No obstante, la posible aparición simultánea de las primeras sepulturas de falsa cúpula en estas comarcas debe considerarse con cautela, dado que la amplia desviación estándar de todas estas dataciones $(\geq$ 100 años) puede estar ocultando diferencias temporales entre ellas.

b) Las últimas deposiciones funerarias se producirían a finales de la Edad del Bronce, entre los siglos IX-VIII cal BC (890-710 cal BC al $68 \%$ de probabilidad), justo cuanto se produjeron las innovaciones culturales que dieron origen a la Edad del Hierro. Tampoco parecen existir diferencias temporales entre las distintas comarcas analizadas. Las dataciones más recientes se corresponden con El Barranquete 11 en Almería y Palacio III en Sevilla. A poca distancia se sitúa Centirã 2 en el Alentejo portugués. La reutilización de sepulturas megalíticas durante la Edad del Bronce y épocas posteriores no es exclusiva de los tholoi, sino que está ampliamente atestiguada en otros tipos de sepulturas megalíticas distribuidas por diferentes comarcas peninsulares (Kalb 1994; Oliveira 2001; Bueno et al. 2004, 2005; Lorrio y Montero 2004; García Sanjuán 2005a, 2005b, 2011; Matalolo 2007; Aranda 2013; Tejedor 2013).

c) Una de las principales características de este fenómeno es su dilatada temporalidad, entre 2000-2213 años (68\% de probabilidad). A lo largo de este periodo los tholoi serían objeto de prácticas rituales de forma continuada, con la excepción quizás de un breve hiatus en torno al c 1550 cal BC, coincidiendo con la crisis de las sociedades del Bronce Pleno, especialmente reconocible en el Sureste peninsular. Si tenemos en cuenta el periodo en el que se concentran la mayor parte de las dataciones, las sepulturas de falsa cúpula son un fenómeno típico de la Edad del Cobre y del Bronce Antiguo y Pleno. La intensidad en el uso ritual de este tipo de sepulturas megalíticas durante la Edad del Bronce es sin duda una de las más importantes aportaciones de las series radiocarbónicas obtenidas en los últimos años. Además, la ausencia de cualquier tipo de hiatus entre las Edades del Cobre y Bronce no solo es observable en la serie radiométrica en su globalidad, sino también en la de sepulturas específicas como El Barranquete 11 y Centirã 2. La continuidad mostrada en ambos casos cuestiona el concepto de reutilización, ya que no parece sostenible mantener una fase de uso con anterioridad al c. $2200 \mathrm{y}$ de reutilización con posterioridad si no se registra ningún tipo de discontinuidad en las deposiciones funerarias y prácticas rituales asociadas.

d) La obtención de series radiocarbónicas para medir la temporalidad de sepulturas específicas ha permitido determinar que la construcción de sepulturas tipo tholos se realizó de forma secuenciada a lo largo de al menos toda la Edad del Cobre, una situación similar a la documentada para otros tipos de sepulturas megalíticas peninsulares (Bueno et al. 2005). Las dos sepulturas que poseen amplias series radiométricas evidencian su tardía construcción, entre el 2452-2317 cal BC (68\% de probabilidad) para El Barranquete 11 y entre el 2525-2334 cal BC (68\% de probabilidad) para Centirã 2. Se 
trata de intervalos de probabilidad distanciados en al menos 500 años de las fechas más antiguas disponibles para este tipo de construcciones monumentales. Además, la tardía construcción de tholoi como El Barranquete 11 implicaría un corto uso funerario durante la Edad del Cobre, entre 75-239 años (68\% de probabilidad), lo que supondría entre tres y nueve generaciones de deposiciones mortuorias (Aranda y Lozano 2014). De esta forma, el análisis de la diacronía de necrópolis como El Barranquete o Los Millares se convierte en un requisito imprescindible para su estudio.

\section{Agradecimientos}

El presente trabajo fue presentado en el III Congreso de Prehistoria de Andalucía. I+D+i en la Prehistoria del sur peninsular (Antequera, 22-24 de octubre de 2014) y forma parte del proyecto de investigación "Innovación, continuidad e hibridación. Las sociedades de las Edades del Cobre y Bronce en el sur de la península ibérica" (HAR2013-42865-P) y del Grupo de Investigación "GEA. Cultura material e identidad social en la Prehistoria Reciente en el sur de la península ibérica" (www.webgea.es). Agradecemos los esclarecedores comentarios y sugerencias realizados por los evaluadores/as anónimos.

\section{BIBLIOGRAFÍA}

Almagro Gorbea, M.J. (1973): El poblado y la necrópolis de El Barranquete (Almería). Madrid, Ministerio de Educación y Ciencia.

Alonso Mathias, J.; Cabrera Valdés, V.; Chapa Brunet, T. y Fernández-Miranda, M. (1978): "Índice de fechas arqueológicas de C-14 para España y Portugal", en M. Almagro Gorbea y M. Fernández-Miranda (eds.), C14 y Prehistoria de la Península ibérica: 155-183. Madrid, Fundación Juan March.

Aranda Jiménez, G. (2013): “Against Uniformity Cultural Diversity: The "Others" in Argaric Societies”, en M. Cruz Berrocal, L. García Sanjuán y A. Gilman (eds.), The Prehistory of Iberia. Debating Early Social Stratification and the State: 99-118. New York, Routledge.

Aranda Jiménez, G. (2015): "Resistencia e involución social en las comunidades de la Edad del Bronce del sureste de la península ibérica". Trabajos de Prehistoria 72(1): 126-144.
Aranda Jiménez, G. y Lozano Medina, A. (2014): “The chronology of megalithic funerary practices: a Bayesian approach to Grave 11 at El Barranquete necropolis (Almería, Spain)". Journal of Archaeological Science 50: 369-382.

Aranda Jiménez, G.; Montón-Subías, S. y Sánchez Romero, M. (2015): The Archaeology of Bronze Age Iberia. Argaric Societies. New York, Routledge.

Bayliss, A.; Bronk Ramsey, C.; Van der Plicht, J. y Whittle, A. (2007): "Bradshaw and Bayes: Towards a Timetable for the Neolithic". Cambridge Archaeological Journal 17(1): 1-28.

Blasco Rodríguez, F. y Ortiz Alesón, M. (1991): “Trabajos arqueológicos en Huerta Montero (Almendralejo, Badajoz)", en Actas de las I Jornadas de Prehistoria y Arqueología en Extremadura 1986-1990, Extremadura Arqueológica II: 129-138. Mérida, Cáceres (1991), Madrid.

Boaventura, R. (2009): As antas e o Megalitismo da região de Lisboa. Tesis Doctoral, Universidad de Lisboa.

Bueno Ramírez, P.; Barroso Bermejo, R. y De Balbín Berhmann, R. (2004): “Construciones megalíticas avanzadas de la cuenca interior del Tajo. El núcleo cacereño". Spal. Revista de Prehistoria y Arqueología 13: 83-112.

Bueno Ramírez, P.; Barroso Bermejo, R. y De Balbín Berhmann, R. (2005): "Ritual campaniforme, ritual colectivo: la necrópolis de cuevas artificiales del valle de Las Higueras, Huescas, Toledo". Trabajos de Prehistoria 62(2): 67-90.

Bronk Ramsey, C. (1995): "Radiocarbon calibration and analysis of stratigraphy: the OxCal program". Radiocarbon 37(1): 425-430.

Bronk Ramsey, C. (2009): "Bayesian Analysis of radiocarbon dates". Radiocarbon 51(1): 337-360.

Cardoso, J.L.; Leitão, M.; Ferreira, O.; North, C.; Norton, J.; Medeiros, J. y Sousa, P. (1996): “O monumento pré-histórico de Tituaria, Moinhos da Casela (Mafra)". Estudos Arqueológicos de Oeiras 6: 135-193.

Delibes de Castro, G. (2004): "La impronta Cogotas I en los dólmenes del Occidente de la cuenca del Duero o el mensaje megalítico renovado". Mainake XXVI: 211-31.

Fernández Flores, A. y Aycart, V. (2013): "Montelirio. Un sepulcro clave para la comprensión del registro de los grandes monumentos megalíticos de Valencina de la Concepción-Castilleja de Guzmán (Sevilla)", en L. García Sanjuán, J.M. Vargas, V. Hurtado, T. Ruiz y R. Cruz-Auñón (eds.), El asentamiento prehistórico de Valencina de la Concepción 
(Sevilla): investigación y tutela en el 150 aniversario del descubrimiento de La Pastora: 233-259. Sevilla, Universidad de Sevilla.

Ferreira, O. da V. y Trindade, L. (1956): "La necrópole de «Cabeço da Arruda» (T. Vedras)", en Congresos Internacionales de Ciencias Prehistóricas y Protohistóricas, Actas de la IV Sesión: 503-520. Madrid (1954), Zaragoza (1956), Zaragoza, Librería General.

García Sanjuán, L. (2005a): “Grandes Piedras Viejas, Memoria y Pasado. Reutilizaciones del Dolmen de Palacio III (Almadén de la Plata, Sevilla) durante la Edad del Hierro", en Protohistoria del Mediterráneo Occidental. III Simposio Internacional de Arqueología de Mérida. Anejos de Archivo Español de Arqueología 35: 595-604. Mérida (2003), Mérida, CSIC.

García Sanjuán, L. (2005b): "Las piedras de la memoria. La permanencia del megalitismo en el suroeste de la Península ibérica durante el II y I milenios ANE". Trabajos de Prehistoria 62(1): 85-109.

García Sanjuán, L. (2006): "Funerary ideology and social inequality in the Late Prehistory of the Iberian South-West (c. 3300-850 cal BC)”, en P. Díaz del Río y L. García Sanjuán (eds.), Social Inequality in Iberian Late Prehistory. British Archaeological Report International Series 1525: 149-170. Oxford, Archaeopress.

García Sanjuán, L. (2009): "Sevilla", en L. García y B. Ruiz (eds.), Las grandes piedras de la Prehistoria. Sitios y paisajes megalíticos de Andalucía: 228259, Sevilla, Consejería de Cultura de la Junta de Andalucía.

García Sanjuán, L. (2011): “Transformations, Invocations, Echoes, Resistance: The Assimilation of the Past in Southern Iberian Monumental Landscapes (V to I millennia BC)", en K. Lillios (ed.), Comparative Archaeologies. The American Southwest (AD 900-1600) and the Iberian Peninsula (3000-1500 $B C$ ): 81-102. Oxford and Oakville, Oxbow Books.

García Sanjuán, L.; Scarre, C. y Wheatley, D.W (eds.) (2011): Exploring Time and Matter in Prehistoric Monuments: Absolute Chronology and Rare Rocks in European Megaliths. Proceedings of the 2nd European Megalithic Studies Group Meeting. Menga: Revista de Prehistoria de Andalucía, Monograph 1. Sevilla (2008), Sevilla.

Gomes, M.V.; Cardoso, J.L. y Cunha, A.S. (1994): “A sepultura de Castro Marim". Comunicações do Instituto Geológico e Mineiro 80: 99-105.

Gonçalves, V.S. (2006): "Some questions about time, space and megalithic symbols in the centre and the south of Portugal", en R. Joussaume, L. Laporte y C. Scarre (eds.), Origin and Development of the Megalithic Monuments of Western Europe: 485510, Bougon, Musée des Tumulus de Bougon.

Hurtado Pérez, V.; Mondejar, P. y Pecero Espín, J.C. (2000): "Excavaciones en la Tumba 3 de La Pijotilla”, en J.J. Jiménez y J.J. Enríquez (eds), El Megalitismo en Extremadura. Homenaje a Elías Diéguez Luengo, Extremadura Arqueológica VIII: 249-266, Mérida, Junta de Extremadura.

Kalb, P. (1994): "Reflexões sobre utilização de necrópoles megalíticas na Idade do Bronze", en $O$ megalitismo no Centro de Portugal. Actas do Seminario. Estudios Pré-Históricos II: 415-26. Mangualde (1992), Viseu, Centro de Estudios Pré-históricos da Beira Alta.

Kalb, P. (1981): “Zur relativen Chronologie portugiesischer Megalithgräber". Madrider Mitteilungen 22: 55-77.

Lorrio Alvarado, A.J. y Montero Ruiz, I. (2004): "Reutilización de sepulcros colectivos en el sureste de la Península Ibérica: la colección Siret". Trabajos de Prehistoria 61(1): 99-116.

Leisner, G. y Leisner, V. (1943): Die Megalithgraber der Iberischen Halbinsel: Der Suden. Berlín, Walter de Gruyter.

Leisner, V. y Ferreira, O. da V. (1963): "Primeiras datas de rádiocarbono 14 para a cultura megalítica portuguesa". Revista de Guimarães 73: 358-366.

Maicas Ramos, R. (2007): Industria ósea y funcionalidad: Neolítico y Calcolítico en la Cuenca de Vera (Almería). Madrid, Consejo Superior de Investigaciones Científicas.

Márquez Romero, J.E. (2009): “Málaga”, en L. García y B. Ruiz (eds.), Las grandes piedras de la Prehistoria. Sitios y paisajes megalíticos de Andalucía: 198-227. Sevilla, Consejería de Cultura de la Junta de Andalucía.

Mataloto, R. (2007): "Paisagem, memoria e identidade: tumulações megalíticas no pós-megalitismo alto-alentejano". Revista Portuguesa de Arqueologia 10(1): 123-40.

Odriozola, C.; Hurtado Pérez, V.; Dias, M.I. y Prudêncio, M.I. (2008): "Datación por técnicas luminiscentes de la Tumba 3 y el conjunto campaniforme de La Pijotilla (Badajoz, España)", en VII Congreso Ibérico de Arqueometría: 211-225. Madrid (2007), Madrid, CSIC.

Oliveira, C. (2001): Lugar e Memória. Testemunhos megalíticos e leituras do Passado. Lisboa, Edições Colibri. 
Reimer, P.J.; Bard, E.; Bayliss, A.; Beck, J.W.; Blackwell, P.G.; Bronk Ramsey, C.; Grootes, P.M.; Guilderson, T.P.; Haflidason, H.; Hajdas, I.; Hattž, C.; Heaton, T.J.; Hoffmann, D.L.; Hogg, A.G.; Hughen, K.A.; Kaiser, K.F.; Kromer, B.; Manning, S.W.; Niu, M.; Reimer, R.W.; Richards, D.A.; Scott, E.M.; Southon, J. R.; Staff, R.A.; Turney, C.S.M. y Van Der Plicht, J. (2013): "IntCal13 and Marine 13 Radiocarbon Age Calibration Curves 0-50,000 Years cal BP”. Radiocarbon 55(4): 1869-1887.

Renfrew, C. (1973): Before Civilization. Londres, Jonathan Cape.

Renfrew, C. (1979): Problems in European Prehistory. Edimburgo, Edinburgh University Press.

Robles, F.J.; Monge, A.M.; Alves, F.; Curate, F.; Valério, P. y Peleja, S. (2013): “O Tholos Centirã 2 (Brinches, Serpa) - construtores e utilizadores; práticas funerárias e cronologías", en VI Encuentro de Arqueología del Suroeste: 319-356. Villafranca de los Barros (2012), Villafranca de los Barros, Ayuntamiento.

Schwabedissen, H. y Freundlich, J. (1966): "Köln Radiocarbon Measurements I". Radiocarbon 8: 239-247.

Silva, A.M. (2012): Antropologia Funerária e Paleobiologia das Populações Portuguesas (Litorais) do Neolítico Final/Calcolítico. Lisboa, Fundação Calouste Gulbenkian.

Siret, L. (1891 [2001]): L'Espagne préhistorique. Almería, Consejería de Cultura de la Junta de Andalucía.
Siret, L. (1906-07 [1994]) : “Orientaux et Occidentaux en Espagne aux temps préhistoriques". Revue des Questions Scientifiques X-XI: 1906: 1529-1582, 1907: 1219-1269.

Soares, A.M. (1999): "Megalitismo e Cronologia Absoluta", en II Congreso de Arqueología Peninsular: 689-706. Zamora (1996), Zamora, Fundación Rei Afonso Henríques.

Soares, A.M. y Cabral, J.M.P. (1984): “Datas convencionais de radiocarbono para estações arqueológicas portuguesas e a sua calibração: revisão crítica". O Arqueólogo Português, $4^{\mathrm{a}}$ série, 2: 167-214.

Tejedor Rodríguez, C. (2013): "La pervivencia de los "usos megalíticos" en el Valle del Duero a lo largo de la Prehistoria Reciente (III-II milenio a.C.). Una aproximación al estudio en la región del Alto Douro", en J. C. Sastre Blanco, R. Catalán Ramos y P. Fuentes Melgar (eds.), Arqueología en el Valle del Duero. Del Neolítico a la Antigüedad tardia: nuevas perspectivas: 33-40. Madrid, Ed. La Ergástula.

Valera, A.C.; Lago, M.; Duarte, C. y Evangelista, L.S. (2000): “Ambientes funerários no complexo arqueológico dos Perdigões: uma análise preliminar no contexto das práticas funerárias calcolíticas no Alentejo". Era-Arqueología 2: 84-105.

Zbyszewski, G. y Ferreira, O. da V. (1967): "Acerca duma "tholos" encontrada em Castro Marim". $O$ Arqueólogo Português III (I): 11-17. 